\title{
Mentoring in biostatistics: some suggestions for reform
}

\author{
This article was published in the following Dove Press journal: \\ Journal of Multidisciplinary Healthcare \\ 12 October 2012 \\ Number of times this article has been viewed
}

\section{Adefowope Odueyungbo' Lehana Thabane ${ }^{2}$ \\ 'Department of Biostatistics, Vertex Pharmaceuticals, Cambridge, MA, ${ }^{2}$ Department of Clinical Epidemiology and Biostatistics, McMaster University, and Biostatistics Unit, Father Sean O'Sullivan Research Centre/Centre for Evaluation of Medicines, St Joseph's Healthcare Hamilton, ON, Canada}

Correspondence: Lehana Thabane Department of Clinical Epidemiology and Biostatistics, McMaster University, Hamilton, ON, Canada

Email thabanl@mcmaster.ca
Abstract: Mentoring is routinely used as a tool to facilitate acquisition of skills by new professionals in fields like medicine, nursing, surgery, and business. While mentoring has been proposed as an effective strategy for knowledge and skills transfer in biostatistics and related fields, there is still much to be done to facilitate adoption by stakeholders, including academia and employers of biostatisticians. This is especially troubling given that biostatisticians play a key role in the success or otherwise of clinical research conducted for evidence-based decisions. In this paper, we offer suggestions on how mentoring can be applied in practice to advance the statistical training of future biostatisticians. In particular, we propose steps that academic statistics departments, professional statistical societies, and statistics organizations can take to advance the mentoring of young biostatisticians. Our suggestions also cover what mentors and mentees can do to facilitate a successful mentoring relationship.

Keywords: mentoring, biostatistics, career development

\section{Introduction}

The International Statistical Institute, a worldwide network of statisticians in a variety of theoretical and applied sciences, aims to promote the understanding, development, and good practice of statistics worldwide. ${ }^{1}$ This objective is replicated, albeit in different forms, across major regional statistical associations, including the American Statistical Association (ASA) and the Statistical Society of Canada. To achieve this mission, the former president of the International Statistical Institute, Niels Keiding, noted that, among other things, "We need to maintain an up-to-date development of young statisticians". ${ }^{1}$ Mentoring is a process that can be useful for encouraging human development, whereby individuals invest time and resources to advance the personal and professional growth and abilities of other individuals for the advancement of organizational or societal goals. In general, mentors are regarded as helpers, ie, persistent encouragers whose primary task is to help others attain their full potential in life's endeavors.

Traditionally, mentoring is viewed as a relationship between older and younger persons, in which the older person guides the younger person in acquiring the survival skills necessary for climbing the career ladder. Contemporarily, mentoring is universally accepted as a process that can occur between any two people, regardless of age, where the mentor offers insight, wisdom, understanding, perception, or knowledge to the mentee. It can also be a simple relationship in which two professionals exchange information to help each other. ${ }^{2,3}$ While mentoring can occur spontaneously and unconsciously, it can also be structured into a formal short-term or long-term 
relationship. Figure 1 provides an overview of the potential roles that a mentor can play along a mentee's career development path.

Mentoring is routinely used in many disciplines to transmit key professional skills from mentors to protégés, including in medicine, ${ }^{4-6}$ nursing, and ${ }^{7-10}$ surgery. ${ }^{11-14}$ It is also advocated as a useful approach by which younger generations can learn from older ones for the advancement of science. ${ }^{15-17}$ We recently called for the mentoring of young statisticians as a way to facilitate their acquisition of important career skills, ${ }^{18}$ and offered suggestions on how potential mentees can choose a mentor and how mentors can help their mentees.

Biostatisticians play a key role in clinical research teams evaluating new drugs or medical devices or surgical procedures for both safety and efficacy/effectiveness. The roles of biostatisticians include: assisting clinicians in formulating the research question; helping to design clinical trials capable of addressing specific research questions; sample size estimation; writing statistical analysis plans; creating data collection strategies; and interpretation of results from statistical models. While foundational theoretical skills required of all biostatisticians can be acquired in a formal academic setting, important characteristics like knowledge of a particular therapeutic research area (eg, oncology), leadership aptitude, statistical consulting, cross-functional collaboration, and other soft skills are obtained by knowledge transfer and years of practical experience. The aforegoing underscores the need for more experienced biostatisticians and stakeholders to encourage mentorship programs proactively, to ensure that upcoming practitioners possess the requisite skills to collaborate successfully with other functions involved in clinical research, especially given the current fast-paced and dynamic health research landscape.

The objectives of this paper are to highlight the need for an active approach to mentoring in biostatistics and related fields in academia, industry, the private sector, and government, and to offer suggestions on how mentoring can be used to advance the statistical training of future biostatisticians. Further, we propose steps that academic statistics departments, professional statistical societies, and statistics organizations can take to advance the mentoring of young biostatisticians.

\section{Literature on mentoring in biostatistics and related fields}

We conducted a literature search in the relevant databases, including PubMed, Journal Storage, and Web of Science, to identify articles on mentoring in biostatistics and related fields. We also searched for gray literature from the Internet using the Google search engine. The following terms were included in the search strategy: "mentoring", "mentorship", "mentor", "mentee", "statistician", "biostatistician", "biostatistics",

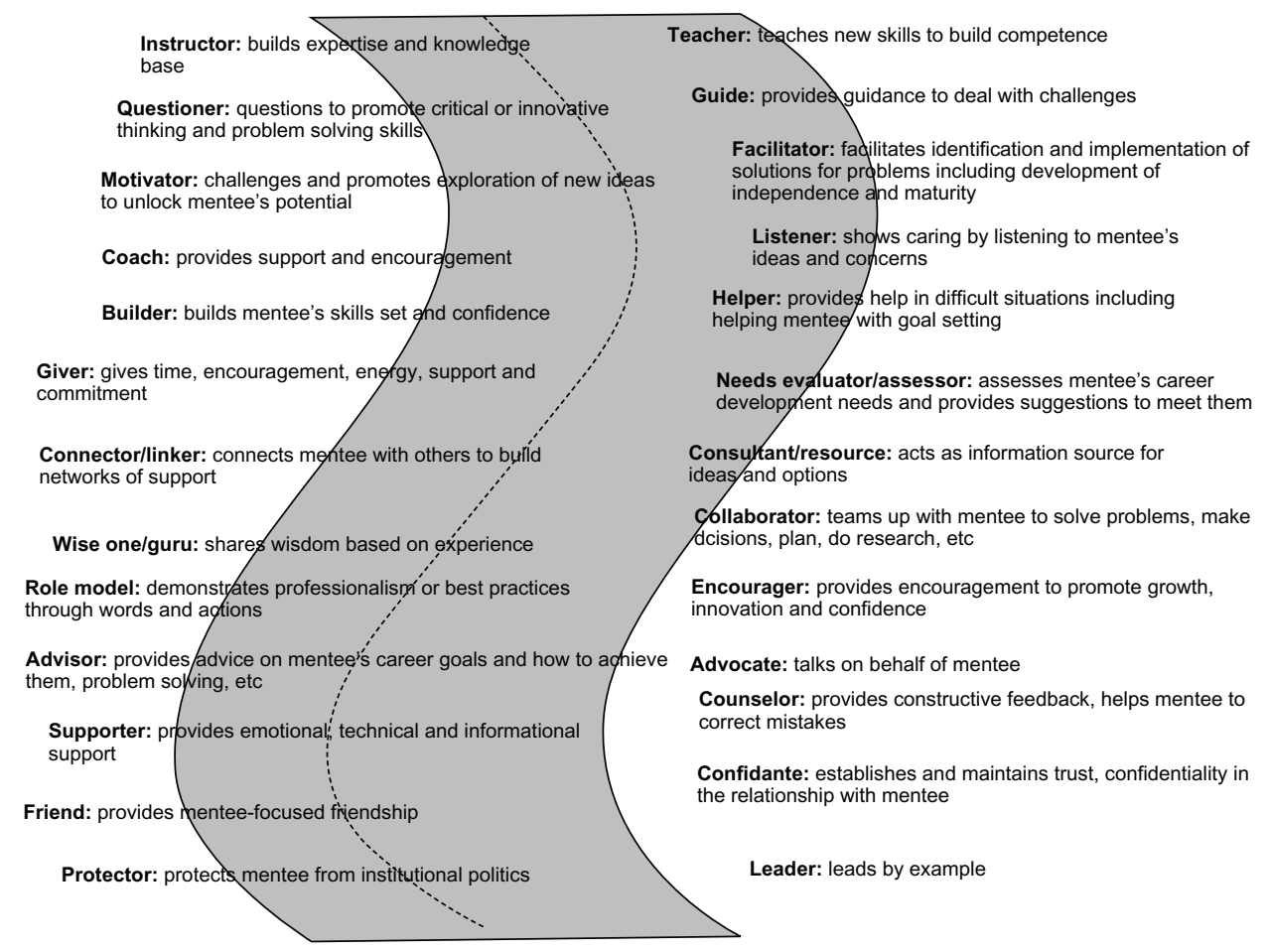

Figure I Potential roles of a mentor along a career development path. 
"statistics", "epidemiologist", and "epidemiology". The search terms were combined using Boolean operators "or" and "and" to create a search strategy. The results of the search are displayed in Table 1.

One reviewer performed a quick scan of retrieved article titles and abstracts to identify articles fulfilling at least one of the following criteria:

- empirical study on the prevalence of mentorship in statistics, biostatistics, or epidemiology;

- empirical study on the relationship between mentorship and career development in statistics, biostatistics, or epidemiology.

Although not of primary interest, articles that discussed the prevalence of mentorship in medical disciplines or the relationship between mentorship and career development in medical disciplines were also retained.

Overall, none of the retrieved articles discussed prevalence of mentorship in statistics, biostatistics, or epidemiology. Further, none of the studies reported any empirical evidence of an association between mentorship and career development in statistics, biostatistics, or epidemiology. Thabane et $\mathrm{al}^{18}$ was the only article that specifically addressed mentoring

Table I Number of hits in literature search as of August 20, 2012

\begin{tabular}{|c|c|c|}
\hline Search strategy & Database & Hits \\
\hline (Mentoring OR mentorship OR mentor OR & PubMed & I \\
\hline \multirow[t]{2}{*}{ mentee) AND statistician } & JSTOR & 701 \\
\hline & WOS & II \\
\hline (Mentoring OR mentorship OR mentor OR & PubMed & 0 \\
\hline \multirow[t]{2}{*}{ mentee) AND biostatistician } & JSTOR & 95 \\
\hline & WOS & 0 \\
\hline (Mentoring OR mentorship OR mentor OR & PubMed & 14 \\
\hline \multirow[t]{2}{*}{ mentee) AND biostatistics } & JSTOR & 661 \\
\hline & WOS & 10 \\
\hline (Mentoring OR mentorship OR mentor OR & PubMed & 721 \\
\hline \multirow[t]{2}{*}{ mentee) AND statistics } & JSTOR & 9518 \\
\hline & WOS & 89 \\
\hline (Mentoring OR mentorship OR mentor OR & PubMed & 722 \\
\hline \multirow[t]{2}{*}{ mentee) AND (statistics or statistician) } & JSTOR & 9642 \\
\hline & WOS & 96 \\
\hline (Mentoring OR mentorship OR mentor OR & PubMed & 14 \\
\hline \multirow[t]{2}{*}{ mentee) AND (biostatistics or biostatistician) } & JSTOR & 682 \\
\hline & WOS & 10 \\
\hline (Mentoring OR mentorship OR mentor OR & PubMed & 3 \\
\hline \multirow[t]{2}{*}{ mentee) AND epidemiologist } & JSTOR & 287 \\
\hline & WOS & 6 \\
\hline (Mentoring OR mentorship OR mentor OR & PubMed & 342 \\
\hline \multirow[t]{2}{*}{ mentee) AND epidemiology } & JSTOR & 1646 \\
\hline & WOS & 41 \\
\hline (Mentoring OR mentorship OR mentor OR & PubMed & 343 \\
\hline \multirow[t]{2}{*}{ mentee) AND (epidemiology or epidemiologist) } & JSTOR & 1702 \\
\hline & WOS & 43 \\
\hline
\end{tabular}

Abbreviations: JSTOR, Journal Storage; WOS, Web of Science. of statisticians, although the authors did not address the effect of mentoring on career development. Several papers called for curriculum reform to train statisticians to have the skill set appropriate for the roles they play in science and research. ${ }^{19-27} \mathrm{~A}$ few dealt with issues of career development for statisticians working in the pharmaceutical industry ${ }^{28,29}$ and research $^{30}$ and for women in academia. ${ }^{17}$

We also found two systematic reviews on mentorship, but none directly relevant to biostatistics. The first study systematically reviewed evidence concerning the prevalence of mentorship and its relationship to career development in academic medicine. ${ }^{31}$ The conclusion was that although mentoring is perceived as an important part of academic medicine, the evidence to support a correlation between mentoring and career growth is not strong. The findings from the second review were somewhat similar. ${ }^{32}$ They were generally supportive of the benefits (ie, compensation and career satisfaction) associated with mentoring, although the effect sizes were small and differed in magnitude depending on the type of mentoring provided (ie, career or psychosocial). The overall message from both reviews was that further studies using more rigorous methods, addressing contextual issues, and using cross-disciplinary approaches are needed to assess the effect of mentoring on career development and related outcomes. The field of biostatistics would certainly benefit from such studies as well. However, it is important to note that "absence of evidence is not evidence of absence". ${ }^{33}$ There is substantial anecdotal evidence to suggest that mentoring is a key ingredient in career development.

\section{Mentoring in practice: suggestions for reform}

Here we offer suggestions on how the different players, ie, statistics/biostatistics departments, statistical societies, biostatistician employers, mentors, and mentees, can each utilize mentoring ideas to advance the practice of biostatistics.

\section{What can statistics departments do?}

Incorporating mentoring into graduate training can be a useful tool to complement formal course work with individualized hands-on (practical) experience and career counseling. Thabane et $\mathrm{al}^{34}$ documented their experience in developing a biostatistical collaboration course aimed at graduate students in the health research methodology $\mathrm{PhD}$ program (biostatistics specialization) at the Department of Clinical Epidemiology and Biostatistics at McMaster University, Canada. The course uses a combination of lectures and tutorials led by faculty members, videotaped consulting 
practice sessions, and an internship component, with mentoring of each student by an experienced faculty biostatistician. Bangdiwala ${ }^{35}$ described the mentoring process of the graduate students in apprenticeship research assistant positions in the Department of Biostatistics, School of Public Health, University of North Carolina at Chapel Hill. In both cases, the authors argue that inclusion of a mentoring component in graduate education can greatly enhance the learning experiences of biostatistics students to prepare them for the real world.

Thabane et $\mathrm{al}^{36}$ proposed an overhaul of the statistics curriculum for the development of statistics in developing countries. Among other things, they recommended the creation of SPAIGA (Statistics Partnership among Academe, Industry, and Government in Africa) to advance collaboration between industry, government, and academia and improve statistical training and capacity building in developing continents like Africa. ${ }^{36}$ This was based on the SPAIG model which has been in place in the US for some time and seems to be working effectively. ${ }^{37,38}$ They also called for extensive curriculum reform to include mentoring and internships as part of regular training for young statisticians.

The cooperative (co-op) education model is often used in engineering and business administration departments to expose students to real-life, practical, and relevant experience within government or industry. During cooperations, students acquire useful skills that extend beyond the "classroom learning experience" and are ideally better prepared for work out of school. We encourage statistics/ biostatistics departments to explore the co-op strategy as a way to enrich the learning experience of students. From our experience as university faculty members and employers, many fresh statistics graduates are grossly underprepared for the challenges outside a solely theory-driven course work curriculum.

\section{What can statistical societies or associations do?}

Advancement of the statistics field is one of the key goals of any statistical society. There are many things that statistical societies can do to achieve this goal. Examples include:

- Introduction of an accreditation process that includes mentoring of young professionals by experienced biostatisticians. Several associations or societies, including the Statistical Society of Canada and the Royal Statistical Society, already have accreditation processes that include mentoring to support budding professional statisticians.

- Offering regular courses on mentoring to both mentors and mentees.

First, potential mentors need to be trained to acquire the skills and knowledge of how to become good mentors. Second, trainees need to learn how to select a mentor. Third, both mentors and mentees need to learn how to have successful mentorship relationships. It is the role of professional associations to advance the mentoring skills of members through continuing education.

- Organizing special yearly sessions on mentoring led by experienced mentors. It is important to recognize that mentors also need to be mentored to be effective in their role.

- Offering mentorship awards as incentives to good mentors, and to encourage potential mentors to participate in developing the next generation of biostatisticians. For example, ASA has established a mentoring award, ie, the Jeanne E Griffith mentoring award, to encourage mentoring of junior staff in the US federal statistical system.

- Providing scholarships/travel awards to students to attend workshops on mentoring organized or sponsored by statistical societies.

- Providing job interview opportunities for recent graduates. ASA has been very proactive in providing such opportunities for job seekers at the annual joint statistical meetings held in different cities across the US. Registered members of ASA also receive a monthly magazine in which employers advertise various openings in the industry, government, and academia, thus providing an avenue for job seekers to explore opportunities in the statistics field.

- Statistical associations can also collaborate with industry to create internship programs that provide opportunities for students to encounter real-work scenarios and solve real-life problems. ASA has created an annual summer internship program that matches students with employers for internship opportunities in the pharmaceutical industry. ASA internship programs provide a great opportunity for students to acquire skills that may be useful in their future careers. It also provides an opportunity for employers to explore potential employment relationships with their interns. Other statistical associations (such as the Statistical Society of Canada) can promote the growth of the biostatistics profession in their various 
geographical locations by adopting the ASA internship model.

\section{What can national statistics offices/bureaus or other statistician employers do?}

Mentoring can be especially helpful in national statistics offices, universities, the pharmaceutical industry, and research institutions, or any organization that hires biostatisticians. Employers should consider having a mentorship program aimed at helping new recruits build successful careers. Such a program would pair each new recruit with an appropriate mentor, providing the necessary resources and support for the relationship to succeed. Special mentor recognition programs should be created to recognize or acknowledge the contributions made by the mentor in building a successful work environment for the employer through mentoring others.

Second, leadership exchange programs between national statistical offices should be created as a way to share knowledge and skills on best practices around mentoring. National statistical institutions from developing countries may benefit from manpower development in modern techniques of data collection and analysis by successful regional institutions like Statistics Canada and FedStats in the US. Thabane et $\mathrm{al}^{36}$ have suggested that such programs can be organized within and across countries.

Third, use of journal clubs to share ideas from the literature on mentoring and other statistical issues can enhance mentoring relationships. Journal clubs can also be useful in cultivating a healthy research culture within an organization, if research is an important part of the organization's lifeblood. For instance, journal clubs can be used to discuss how to turn certain work-related problems into researchable questions, something that is not so simple for novice researchers. ${ }^{39}$

Lastly, regular inhouse workshops or courses on leadership, management, mentoring, communication, and working in teams can promote the acquisition of nonstatistical skills for biostatisticians. As mentioned earlier, such skills are not usually taught in regular statistics training programs, but are essential for biostatisticians to collaborate or work effectively with other professionals who do not have a background in statistics. The US Food and Drug Administration is an organization charged with the responsibility of evaluating data from clinical trials designed to investigate the efficacy/effectiveness of new therapies for potential marketing approval in the US, and offers an annual workshop to train statisticians and allied professionals in the clinical research process concerning issues such as multiplicity adjustments and interim analysis in clinical trials. Food and Drug Administration workshops, for instance, provide opportunities for young statisticians to acquire new skills and help practicing statisticians to gain a deeper understanding of recent developments in the field.

\section{What can mentors do for their mentees?}

Mentors can start by providing opportunities for their mentees to "job-shadow" them. As an old Chinese proverb says, "Tell me, I'll forget. Show me, I'll remember. Involve me, I'll understand". By showing and involving mentees in some of their daily activities, mentors can create a fertile learning environment for mentees. For example, in an academic setting, a mentor can introduce their mentee to manuscript or grant reviewing by doing it together with them the first time, and independently afterwards with a plan to compare notes. They can also provide an opportunity for a mentee to attend a scientific review committee meeting as a guest or mentee reviewer under their guidance. A mentor can also play a major role in expanding the mentee's social and professional network by introducing the mentee to key individuals within and outside the work environment. Other roles include:

- providing feedback to a mentee on presentations and reports;

- protecting the mentee against institutional politics or "office politics" in both academic and other settings;

- advising the mentee on how to identify researchable ideas and how to frame them into research questions if the mentee is part of a research-intensive institution, like academia;

- counseling the mentee about career goals; not many recent graduates know exactly what career pathway they should take, and a mentor may help to identify prospective career opportunities;

- providing opportunities for mentees to participate in clinical research teams where they can learn to collaborate with experts from various backgrounds (clinicians, epidemiologists, programmers, database analysts), contribute to advancing research questions and study protocols, obtain experience in sample size estimation, and develop skills to author statistical analysis plans independently; they also have an opportunity to be coauthors on research successfully developed by their teams based on their level of contribution to individual projects;

- providing opportunities for mentees to participate in data safety monitoring boards as understudies; data safety monitoring boards not only provide regulatory agencies and research ethics boards with much needed help in ensuring that research subjects are not unduly exposed 
to unsafe/ineffective therapies, they also ensure that highly effective therapies are not perpetually stuck in an unjustifiably prolonged clinical research process; as part of data safety monitoring boards, biostatisticians provide guidance on the proper use of statistical stopping rules, multiplicity adjustment, and sample size theory to help the committee reach informed decisions;

- helping to assess the mentee's curriculum vitae (for students or job seekers) and provide useful feedback and suggestions on how to make it more attractive to potential employers.

Thabane et al provide details on how mentors can effectively perform some of the above roles. ${ }^{18}$

\section{What can mentees do for themselves?}

Another Chinese proverb says "Teachers open the door. You enter by yourself." Such is true of any mentoring relationship. To a great extent, the success of a mentorship relationship depends partly on how well the mentee follows the advice and takes advantage of the opportunities provided by their mentor. Thabane et $\mathrm{al}^{18}$ provide suggestions on what mentees can do for themselves. ${ }^{18}$ These include:

- developing a habit of reading as a way to expand their knowledge base;

- attending appropriate professional meetings to network with other professionals; the annual joint statistical meetings and Statistical Society of Canada gatherings are just a few of the many opportunities available in the US and Canada, respectively;

- attending workshops or short courses on nonstatistical topics such as time management, mentoring, financial management, conflict resolution, and supervising people, all of which are key to a successful career in any field, but are often neglected in biostatistics;

- giving interdepartmental seminars as a way to learn about the culture of other fields and research collaborators, eg, a biostatistician in a pharmaceutical company might consider presenting seminars to medical directors and clinical operations groups to foster a more synergistic collaboration within research teams engaged in clinical trials;

- serving on review committees of granting agencies and research ethics boards to advance the biostatistics discipline and help to adjudicate the quality of statistical content in submissions to these groups;

- serving as external reviewers of grant proposals and journal manuscripts; these provide a good opportunity to learn novel methodology and sharpen one's analytical skills by critically appraising work by other scientists;
- acquiring programming skills in at least two statistical software applications; from our experience, the R-package (http://www.r-project.org/) is often preferred in academic settings, where software licensing may be costly and cost-cutting by statistics departments is often desired; however, for biostatisticians intending to proceed to industry (eg, pharmaceutical industry), indepth knowledge of a statistical package like SAS (SAS Institute, Cary, NC) will be useful because this appears to be the software of choice in many companies hiring biostatisticians; the motivation to learn new software applications, depending on the employer's preference, is a quality that all biostatisticians should possess;

- being flexible and motivated to adapt to a changing statistical landscape, where traditional methods of data analysis (eg, traditional analysis of variance models) are being less emphasized in favor of more sophisticated analytic techniques (mixed effects models; pattern-mixture mixed effects models; joint models) for analyzing data from longitudinal and cross-sectional studies.

It is important to recognize that while mentoring can facilitate the acquisition of important career skills, it cannot guarantee success. Individual effort plus mentorship support are key ingredients for success.

\section{Conclusion}

Biostatisticians play a critical role in the gathering, analysis, and interpretation of data for evidence-based decisions in health care research. We have provided some suggestions on how to manage mentor-mentee relationships to advance the practice of biostatistics in both academic and nonacademic settings. Results from a literature search show little or no evidence that mentoring has been systematically used to help biostatisticians acquire important career skills. Though routinely used in medical fields, a recent systematic review suggests that there is little evidence of mentoring being associated with career advancement. However, this speaks mostly to the lack of well-powered, randomized, controlled trials to investigate the effect of mentoring on career development outcomes.

Decades ago, a report by ASA listed the skills of an effective statistician that included: being well trained in the theory and practice of statistics; being an effective problem solver; having good oral and written communication skills; facility with computers; ability to extend and develop statistical methodology; ability to adapt quickly to new problems and challenges; producing high-quality work in a timely 
fashion; and ability to work well in teams. ${ }^{19}$ Given that these skills are not transferable by academic training alone, there needs to be coordination of efforts among academia, industry, government, statistical associations, and opinion leaders in the field to ensure that the younger generation of biostatisticians are equipped to manage the challenges of the 21 st century.

Mentoring of a younger generation of biostatisticians by older ones can greatly facilitate the acquisition of skills key to the development of statistics in every country. We suggest that the use of mentoring could start at the university level by incorporating mentorship components into academic curricula. Statistical associations or societies can also play a role by developing strategic continuing education workshops or courses on mentoring. We encourage biostatistician employers, such as national statistics offices and the pharmaceutical industry, to establish formal mentoring programs as part of their hiring practices to facilitate learning for and retention of young biostatisticians.

\section{Acknowledgments}

We thank the reviewers of the original version of the manuscript for helpful and insightful comments leading to improvement in the structure and content of the revised version. Lehana Thabane is a clinical trials mentor for the Canadian Institutes of Health Research. Adefowope Odueyungbo is a former student and mentee of Lehana Thabane. The study was funded in part by the CANNeCTIN progam.

\section{Disclosure}

The authors report no conflicts of interest in this work.

\section{References}

1. Keiding N. Message from the President. International Statistical Institute Newsletter. 2007;31(91).

2. Mullen EJ. Framing the mentoring relationship as an information exchange. Human Resource Management Review. 1994;4(3):257-281.

3. Mullen EJ, Noe RA. The mentoring information exchange: when do mentors seek information from their protégés? J Organ Behav. 1999;20(2): 233-242.

4. Luckhaupt SE, Chin MH, Mangione CM, et al. Mentorship in academic general internal medicine: results of a survey of mentors. J Gen Intern Med. 2005;20(11):1014-1018.

5. Farrell SE, Digioia NM, Broderick KB, Coates WC. Mentoring for clinician-educators. Acad Emerg Med. 2004;11(12):1346-1350.

6. Rockman P, Salach L, Gotlib D, Cord M, Turner T. Shared mental health care. Model for supporting and mentoring family physicians. Can Fam Phys. 2004;50(3):397-402.

7. Gibson T, Heartfield M. Mentoring for nurses in general practice: an Australian study. J Interprof Care. 2005;19(1):50-62.

8. Hill JJ, Del Favero M, Ropers-Huilman B. The role of mentoring in developing African American nurse leaders. Res Theory Nurs Pract. 2005;19(4):341-356.
9. Tourigny L, Pulich M. A critical examination of formal and informal mentoring among nurses. Health Care Manag (Frederick). 2005; 24(1):68-76.

10. Block LM, Claffey C, Korow MK, McCaffrey R. The value of mentorship within nursing organizations. Nurs Forum. 2005;40(4):134-140.

11. Singletary SE. Mentoring surgeons for the 21st century. Ann Surg Oncol. 2005;12(11):848-860.

12. Hoover EL. Mentoring surgeons in private and academic practice. Arch Surg. 2005;140(6):598-608.

13. Rosser JC Jr, Herman B, Giammaria LE. Telementoring. Semin Laparosc Surg. 2003;10(4):209-217.

14. Gaissert HA, Casale AS, Creswell LL, et al; Society of Thoracic Surgeons Workforce on Clinical Trials. Mentoring clinical trials in thoracic and cardiovascular surgery: a new role for the Society of Thoracic Surgeons. Ann Thorac Surg. 2004;77(5):1874-1875.

15. Alberts B. Science and World's Future. Presented at the 136th Annual Meeting of the National Academy of Sciences, Washington DC, April 26, 1999. Available from: http://www.nasonline.org/site/ DocServer/1999address.pdf?docID=941. Accessed September 18, 2012.

16. Frey BR, Nolles B. Mentoring: a promise for the future. J Cell Biol. 1986;20:49-51.

17. Nolan D. Women in statistics in academia: mentors matter. Stat Sci. 1992;7(2):267-272.

18. Thabane L, Thabane M, Goldsmith $\mathrm{CH}$. Mentoring young statisticians: facilitating the acquisition of important survival skills. Afr Stat J. 2006;2:31-42 (republished with corrections: Afr Stat J. 2007;4:123-136). Available from: http://www.afdb.org/fileadmin/uploads/afdb/ Documents/Publications/African.Statistical.Journal_Vol4_2. Articles_9.MentoringYoungStatisticians.pdf. Accessed September 18, 2012.

19. Committee on Training of Statisticians for Industry Preparing Statisticians for Careers in Industry. Report of the ASA section on statistical education. Am Stat. 1980;34(2):65-75.

20. Tobi H, Kuik DJ, Bezemer PR, Ket R. Towards a curriculum for the consultant biostatistician: identification of central disciplines. Stat Med. 2001;20(24):3921-3929.

21. Iman RL. New paradigms for the statistics profession. JAm Stat Assoc. 1995;90(429):1-6.

22. Hammond D. The training of clinical trials statisticians: a clinician's view. Biometrics. 1980;36:679-685.

23. Hogg RV. Statistical education: improvements are badly needed. Am Stat. 1991;45(4):342-343.

24. Federer WT. Some remarks on statistical education. Am Stat. 1978;32(4):117-121.

25. DeMets DL, Anbar D, Fairweather W, Louis TA, O’Neill RT. Training the next generation of biostatisticians. Am Stat. 1994;48(4):280-284.

26. Watts DG. A program for training statistical consultants. Technometrics. 1970;12(4):737-740.

27. DeMets DL, Stormo G, Boehnke M, Louis TA, Taylor J, Dixon D. Training of the next generation of biostatisticians: a call to action in the U.S. Stat Med. 2006;25(20):3415-3429.

28. Chuang-Stein C. On-the-job training of pharmaceutical statisticians. Drug Inf J. 1996;30:351-357.

29. Liss CL. Career development of statisticians in the pharmaceutical industry. Drug Inf J. 2003. Available from: http://www.diahome.org/ Tools $/$ Content.aspx?type $=$ eopdf $\&$ file $=\% 2$ Fproductfiles $\% 2 \mathrm{~F} 8357 \% 2 \mathrm{~F}$ diaj_11376.pdf. Accessed September 18, 2012.

30. Altman N, Bankis D, Chen P, et al. Meeting the needs of new statistical researchers. Stat Sci. 1991;6(2):163-174.

31. Sambunjak D, Strauss SE, Murasic A. Mentoring in academic medicine: a systematic review. JAMA. 2006;296(9):1103-1115.

32. Allen TD, Poteet ML, Eby LT, Lentz E, Lima L. Career benefits associated with mentoring for protégés: a meta-analysis. J Appl Psychol. 2004;89(1):127-136.

33. Altman DG, Bland JM. Absence of evidence is not evidence of absence BMJ. 1995;311(7003):485. 
34. Thabane L, Walter SD, Hanna SE, Goldsmith CH, Pullenayegum E. Development of a biostatistical collaboration course in health sciences research methodology program. J Stat Educ. 2008;16(2): $1-16$.

35. Bangdiwala SI. Mentoring graduate students in apprenticeship positions as research assistants: experience from at the University of North Carolina at Chapel Hill. ICOT-7; 2006. Available at: http://www.stat. auckland.ac.nz/ iase/publications/17/3C3_BANG.pdf. Accessed September 17, 2012.

36. Thabane L, Chinganya O, Ye C. Training young statisticians for the development of statistics in Africa. Afr Stat J. 2008;7:125-148.
37. Statistical partnerships among academe, industry and government. Available from: http://orgs.svsu.edu/spaig/awards.html. Accessed September 17, 2012.

38. Peck R, Haugh LD, Goodman A. Statistical Case Studies: A Collaboration Between Academe and Industry. Philadelphia, PA: The American Statistical Association (ASA) and Society for Industry and Applied Mathematics (SIAM); 1998.

39. Thabane L, Thomas T, Ye C, Paul J. Posing the research question - not so simple. Can J Anaesth. 2009;56(1):71-79.

\section{Publish your work in this journal}

The Journal of Multidisciplinary Healthcare is an international, peerreviewed open-access journal that aims to represent and publish research in healthcare areas delivered by practitioners of different disciplines. This includes studies and reviews conducted by multidisciplinary teams as well as research which evaluates the results or conduct of such teams or healthcare processes in general. The journal covers a wide range of areas and welcomes submission from practitioners at all levels, from all over the world. The manuscript management system is completely online and includes a very quick and fair peer-review system. Visit http://www.dovepress.com/testimonials.php to read real quotes from published authors.

Submit your manuscript here: http://www.dovepress.com/journal-of-multidisciplinary-healthcare-journal 